the process and mechanism of organic evolution independently of any Museum exhibits. Dr Patterson is splendidly eclectic and suitably acerbic in his reviews of the concepts and controversies that contribute to our present understanding of the diversity of life.

As is proper for a taxonomist, Dr Patterson begins with a discussion of the idea of species; and as is proper for a palaeontologist, his concept of a species is three-dimensional (based on "community of descent" rather than "community of resemblance"), and includes the reality of intraspecific variation and differentiation. This leads him on to three chapters on basic genetics, and a further three on ecological and population genetics, culminating in a description of the origin of species -the subject which Darwin did not cover in his book on the Origin of Species; and then to a description of speciation in the Galapagos Islands. The last third of the book contains chapters on evolution beyond the species level, proof and disproof (in which Patterson largely discounts the Popperian view that evolution is metaphyics rather than science), the origin and early evolution of life, evolution and man (sadly playing down de Beer's arguments about neoteny in favour of regulatory genes, which amount to the same thing but are much more difficult to visualise), and a Who's Who of significant evolutionists (largely illustrated with portraits from the Linnean Society's collection).

The writing is concise but clear. I can think of no other book more suitable as a general introduction to the field of evolution as a whole, or for pre-university examinations in particular. There is a brief list of "further reading" which will be a useful guide to librarians.

Patterson steers a careful course through the minefield of evolutionary controversy; one of his reasons for claiming evolution is scientific is that the debates and progress pertinent to evolution have been about a series of specific questions - the relationship between ontogeny and phylogeny, the nature of particulate inheritance, the population genetics revolution in the 1930s, DNA in the 1950s and most recently the neutralist/selectionist argument. Hie skirts round the clade and grade dissension which is currently raising the temperature of systematists (Nature, 276, 759-60; 1978). Perhaps the only area in which Patterson is not entirely fair is in the relationship between evolution and Christianity; and he is hardly to be blamed because of the ability with which Christians from Soapy Sammy Wilberforce onwards have obfuscated their position.
The problem about evolution for Christians is that it seems on the surface to dispose of the need for a creator. The naive solutions are in Patterson's words:

"at one extreme the fundamentalist view that evidence of evolution, such as fossils, was built into the newly-created rocks to tempt us or test our faith. At the other extreme is the person to whom evidence of evolution only pushes the activity of the Creator further and further into the past. Both these modifications of the original creation myths are typical evasive moves, avoiding refutation or confrontation by modifying the original theory or erecting subsidiary defensive theories around it".

True, and Patterson comes close to

\section{Appealing astronomy}

Beyond the Moon? Written and presented by Simon Mitton. (ATV: London, 1979.) First programme transmited in the UK: $09.10,21$ April, on ATV (Midlands). Other channels: morning, 22 April, 1979.

IN view of its position as the most 'popular' of the physical sciences, astronomy has all too little television time allocated to it. ATV is therefore to be congratulated on running a sevenpart introductory series, "both for those who are interested in the subject -and those who think they might be." In each programme Simon Mitton, as both writer and presenter, takes up a different strand and develops it from the historical point of view within a loose framework, which begins traditionally enough with the planets, and extends to encompass the stars, life in the Universe, interstellar travel, and the "far future".

The historical aspects are enlivened with biographical details which paint astronomers as real people; one appealing sequence was the summary of Newton's achievements in terms of the illustration on the current $£ 1$ notes. Despite Mitton's breathless enthusiasm, however, the production is too often constrained by a rigid studio format: presenter at desk with TV monitor. The programmes impress most through their studio demonstrations and film sequences. Demonstrations in the planetary programme range from antique orreries to a water bath for floating models of the low-density giant planets. Some of the demonstrations are unfortunately impressive at the expense of basic physics: the buoyancy of a helium balloon in air is adduced as evidence that the Earth's gravity is incapable of retaining helium atoms, and in a comparison of the weights of model gas molecules helium is represented as $\mathrm{He}_{2}$. One surprisingly successful de- a positive approach to the old dispute when he points out that it is equally "depressing to be ... a pointless experiment in protein chemistry or an experiment in ethics, which is the Christian message read from the same nihilist or "nothing but' vicw point".

The logical fallacy of 'nothing buttery' has been recognised at least since the time of Aristotle; the fact that the same event may have more than one cause ought to have been assimiliated by now--by both scientific reductionists and religious simplicists.

R. J. Berry

R. J. Berry is Professor of Genetics at University College, London, UK.

monstration was a simple scale model of the Sun, Earth and Moon, that conveyed powerfully their relative sizes and distances, and the general emptiness of interplanetary space.

Film sequences from the Royal Greenwich Observatory and the Cambridge Institute of Astronomy provide strong links with the realities of observational astronomy. For example, the opening programme, though perhaps biassed to the possibilities open to amateurs at the expense of the excitement of current research, is imaginatively set within the dome of the Isaac Newton Telescope; and in a later sequence, Mitton recounts the story of the discovery of Neptune from the dome of the Northumberland telescope, the instrument with which Challis almost forestalled Galle's identification of this new planet.

Although the series is carefully thought-out, the programmes seem to suffer from the limits on air-time and budget-restrictions: for example, the animations are crude, and some of the studio and film shots should have been retaken. Among the latter are some shots where slips of the tongue have unfortunately been allowed to survive: a light year is described as " 10 million million miles" (rather than kilometres), and Jupiter's 'year' as $13 \mathrm{yr}$ (instead of $11.9 \mathrm{yr}$ ), to take just two early examples. In addition, some viewers may find Mitton's presentation slightly patronising. To take one example, a description of $8 \times 30$ binoculars as "suitable for sport, and all right for ladies to do astronomy" will not be popular in some quarters. And a halfhour programme without interviews, and with only one presenter, can seem very long. Still, astronomy is an exciting subject, and Mitton's enthusiastic presentation is likely to convince even the casual viewer that astronomy is a subject he should learn more about.

Nigel Henbest

Nigel Henhest, formerly a researcher in radio astronomy, is now a freelance journalist. 